Research Paper

\title{
Trigeminal nerve block with alcohol for medically intractable classic trigeminal neuralgia: long-term clinical effectiveness on pain
}

\author{
Kyung Ream Han ${ }^{\bowtie}$, Yun Jeong Chae², Jung Dong Lee², Chan Kim³ \\ 1. Kichan Pain Clinic, Suwon, Korea; \\ 2. Anesthesiology and Pain medicine, Ajou University Hospital, Suwon Korea; \\ 3. Kimchan Hospital, Suwon, Korea. \\ $\triangle$ Corresponding author: painhankr@naver.com \\ (c) Ivyspring International Publisher. This is an open access article distributed under the terms of the Creative Commons Attribution (CC BY-NC) license \\ (https://creativecommons.org/licenses/by-nc/4.0/). See http://ivyspring.com/terms for full terms and conditions.
}

Received: 2016.07.24; Accepted: 2016.11.01; Published: 2017.01.01

\begin{abstract}
Background: Trigeminal nerve block (Tnb) with alcohol for trigeminal neuralgia (TN) may not be used widely as a percutaneous procedure for medically intractable TN in recent clinical work, because it has been considered having a limited duration of pain relief, a decrease in success rate and increase in complications on repeated blocks.

Objectives: To evaluate the clinical outcome of the Tnb with alcohol in the treatment of medically intractable TN.

Methods: Six hundred thirty-two patients were diagnosed with TN between March 2000 and February 2010. Four hundred sixty-five out of 632 underwent Tnb with alcohol under a fluoroscope. Pain relief duration were analyzed and compared in the individual branch blocks. Outcomes were compared between patients with and without a previous Tnb with alcohol.

Results: Tnb with alcohol were performed in a total 710 (1 1 st_465, 2nd_155, 3rd-55, 4th-23, $\left.5^{\text {th }}-8,6^{\text {th }}-4\right)$ cases for a series of consecutive 465 patients during the study period. Forty hundred sixty two out of the 465 patients experienced immediate complete pain relief (99\%) at the first Tnb. Of the 465 patients, 218 patients (46.9\%) did not require any further treatment after the first Tnb with alcohol during an entire study period. One hundred fifty nine (34.2\%) out of the 465 patients experienced recurring pain after the first block, among whom 155 patients received subsequent blocks, and the remaining 4 patients decided to take medication. According to the Kaplan-Meier analysis, the probabilities of remaining pain relief for 1, 2, 3, and 5 years after the procedures were $86.2 \%, 65.5 \%, 52.5 \%$, and $33.4 \%$, respectively. There was no significant difference in the probability of pain relief duration between patients with and without previous Tnb with alcohol. Median $(95 \% \mathrm{Cl})$ pain relief durations of the first and repeated blocks were 39 (36-51) and 37 (28-54) months, respectively. There was no significant difference in occurrence of complications between patients with and without previous Tnb with alcohol $(p<0.076)$. All the complications recovered spontaneously within 6 months. There was no mortality related to the procedure.

Conclusions: Tnb with alcohol for the pain management of TN can provide considerably long lasting pain relief. Repeated Tnb with alcohol has pain relief duration as long as the first block, and seems to produce less complication as well. Tnb with alcohol is a valuable treatment modality of TN as a percutaneous procedure.
\end{abstract}

Key words: trigeminal neuralgia; trigeminal nerve block; alcohol; neurolysis.

\section{Introduction}

Trigeminal nerve block (Tnb) with alcohol was introduced long ago as a treatment method for trigeminal neuralgia $(\mathrm{TN})(1,2)$. but it is not currently as widely used as other percutaneous procedures or 
microvascular decompression (MVD) (3-12). Nevertheless, a small number of authors continue to stress the importance of an alcohol blockade of the trigeminal nerve (13-16). The main reason for reluctance to perform an alcohol block of the trigeminal nerve for the management of $\mathrm{TN}$ appears to be that it provides pain relief for a limited duration only, and that repeated blocks have a lower success and a higher morbidity rate including neuritis (17).

Unfortunately, there is so far no ideal surgical treatment that can relieve a pain attack immediately and completely without any complication or recurrence. Furthermore, studies on the surgical outcomes of percutaneous procedures and MVD for TN have produced disparate results, which appear to depend on study design and the definitions of success and recurrence. Nevertheless, it is generally accepted that MVD provides longer pain relief for TN than any other percutaneous procedure (17). However, unlike any other percutaneous procedures, mortalities continue to be reported in MVD studies. Radiofrequency thermocoagulation (RF) is believed to offer a higher rate of complete pain relief than any other percutaneous procedure, but at a cost of increased complication rates $(18,19)$.

Before making decisions regarding surgical options, it should be considered that $\mathrm{TN}$ has various durations of pain-free intervals and is more common in the elderly, and that procedure-related complications can be serious. Accordingly, treatment decisions for TN must be made carefully after considering the following; patient age and medical conditions, affected branch of the trigeminal nerve, duration of disease and pain, and response to previous treatments as well as patient preference and practitioner's experience.

However, very little information is available in the literature regarding Tnb with alcohol in TN (1,13-16), and therefore, we evaluated the efficacy and related complications of an alcohol block of the trigeminal nerve for the treatment of medically intractable TN. We also examined whether a previous alcohol block affected procedure outcomes.

\section{Methods}

Six hundred thirteen patients were diagnosed with TN during the 10-year period from March 2000 to February 2010 at Ajou University Hospital in South Korea. Four hundred sixty-five out of 613 underwent Tnb with alcohol under a fluoroscope and were retrospectively reviewed. The study was approved by the Institutional Review Board at Ajou University Hospital. Brain MRI was performed in all study patients to rule out the possibilities of a tumor or multiple sclerosis. Thirteen among a total of the 613 patients $(2.1 \%)$ were found to have brain tumor by MRI and were referred to our neurosurgery department for considering surgery. The 600 remaining primary TN patients were provided with a detailed explanation of the study procedures, and 465 of the 600 participated in this study. Sixty-nine patients had low intensity of pain attacks without medication, 42 were tolerable pain with medication and 24 did not accept the study procedure. A total of 465 study patients provided informed consent prior to the study procedures.

Tnb with alcohol were performed in a total 710 (1st-465, $\left.2^{\text {nd }}-155,3^{\text {rd }}-55,4^{\text {th }}-23,5^{\text {th }}-8,6^{\text {th }}-4\right)$ cases for a series of consecutive 465 patients during the study period. All 465 patients fulfilled the diagnostic criteria for TN as detailed in the international classification of headache disorders as follows; paroxysmal pain attacks of facial or frontal pain lasting a few seconds to less than 2 minutes; pain distributed along one or more divisions of the trigeminal nerve; sudden intense, sharp, superficial, stabbing, or burning in pain; severe intensity; the precipitation of pain from trigger areas or by certain daily activities (e.g., eating, talking, facial washing, or brushing teeth); no symptoms between paroxysms; and no clinically evident neurologic deficit (20). Diagnoses were made after a careful history including the evaluation of characteristics of the pain and observation of non-verbal behaviors such as, speech interruption or major aversion to anyone or anything touching the face during an attack of pain while an interview. Atypical facial pain characterized by paresthesia, aching, a boring and nagging pain between paroxysms, pain lasting more than a few minutes, sensory abnormalities, and no pain-free period was judiciously excluded.

All study patients had previously been treated with carbamazepine and/or other anticonvulsants to which they had become refractory or could not tolerate the side effects of the drugs. One hundred forty seven of the 465 patients had undergone previous surgical treatments, such as, an alcohol nerve block, neurectomy, balloon compression, RF, or MVD (Table 1). Some of the patients with previous interventional procedures already having atypical facial pain or severe hypesthesia were excluded.

The Tnbs were performed with fluoroscopic guidance. Peripheral branch blocks including infraorbital $\mathrm{nb}$ (IONB) and supraorbital $\mathrm{nb}$ (SONB) and major branch blocks including maxillary $\mathrm{nb}$ (V2), mandibular $\mathrm{nb}(\mathrm{V} 3)$, and combined maxillary and mandibular $\mathrm{nb}(\mathrm{V} 2+3)$ were performed according to pain site of an individual patient. All study Tnbs were used pure alcohol (Dehydrated Alcohol Injection, USP, Tera Pharmaceuticals, Buena Park, CA, USA) 
after the confirming accurate needle position on the fluoroscopic view (Fig. 1) and diagnostic hypesthesia on the pain site using injection of $1 \%$ lidocaine with same doses of alcohol for neurolytic block. Total volume of alcohol for the Tnbs were; $0.3 \sim 0.5 \mathrm{ml}$ for SONB, $0.5 \mathrm{ml}$ for IONB, $0.5 \sim 1 \mathrm{ml}$ for $\mathrm{V} 2,0.3 \sim 0.7 \mathrm{ml}$ for $\mathrm{V} 3$, and $0.15 \sim 0.2 \mathrm{ml}$ for $\mathrm{V} 2+3$.

The patients were hospitalized and evaluated their pain status immediate and one day after the procedure. All patients stopped pain medication on the first day of procedure and if they did not experience pain relief, the procedure was repeated the next day until there was pain relief.

Success was defined as the achievement of a pain relief state without medication. Recurrence was defined as the return of any pain, regardless of whether it was controlled by medication or required another procedure. Pain relief duration was defined as the time between the achievement of a pain-free

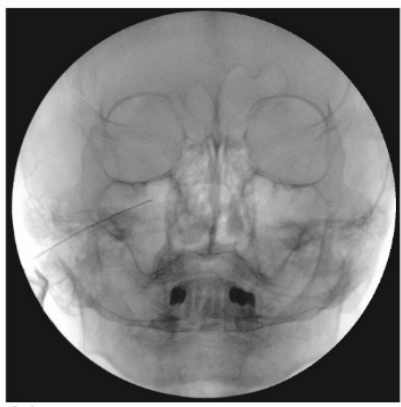

A1
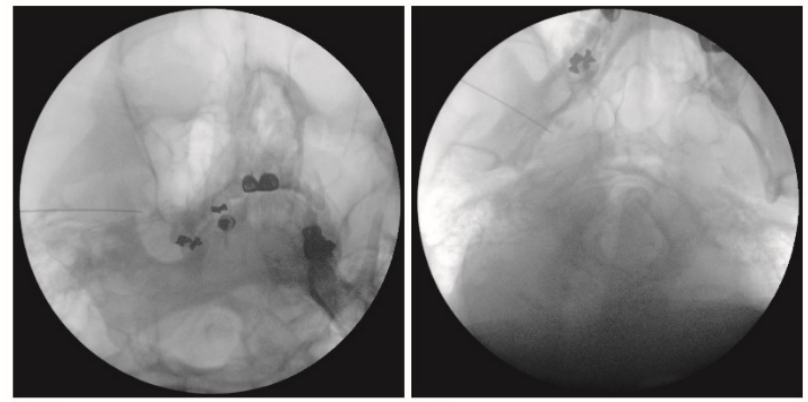

B2

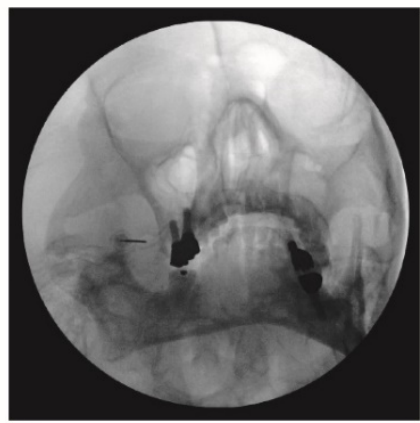

C1

C2 status and the recurrence of pain. Although all study patients experienced hypesthesia in the blocked area after the procedure, almost all patients tolerated decreased sensation, which was not viewed as a complication. Complaints of dysesthesia and loss of sensation were considered as complications of sensory discomfort.

The treatment outcomes were assessed using pain relief duration and complications. We also compared pain relief durations and complications in the study patients with or without previous Tnbs with alcohol. Kaplan-Meier analysis was used to construct pain relief survival curves for censored survival data, and the log-rank test was used to compare the survival curves. The relationships between independent preoperative variables and treatment outcomes were determined by multiple cox regression analysis. Statistical significance was accepted for $\mathrm{p}$ values of $<0.05$.
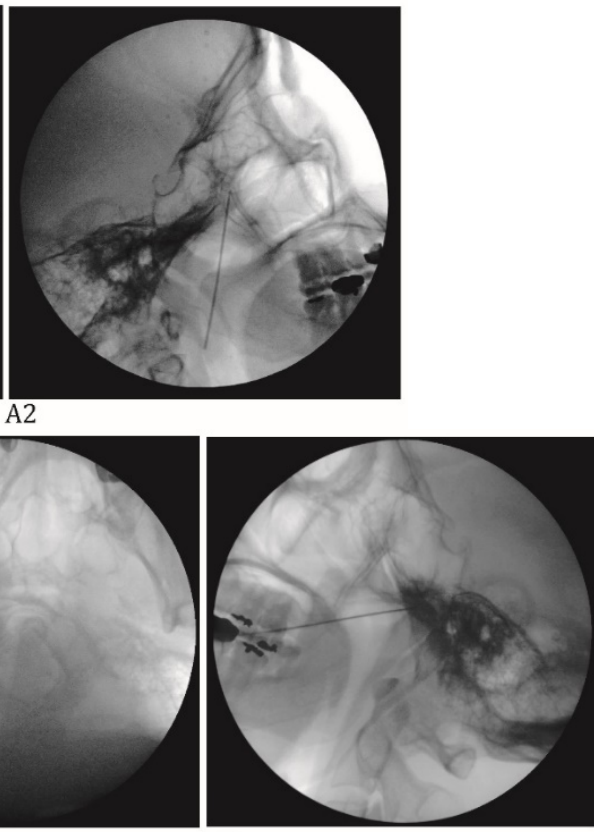

B3

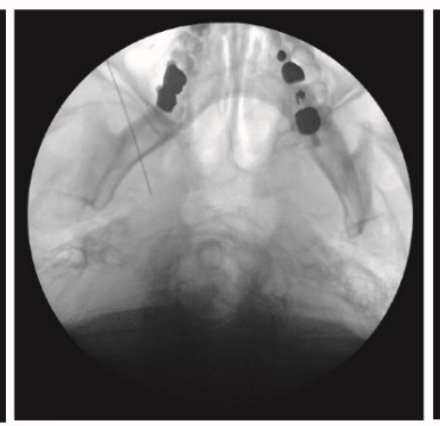

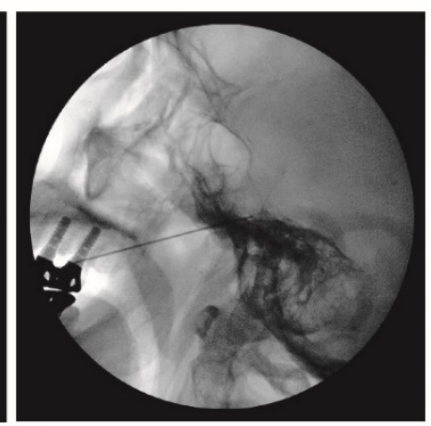

C3

Figure 1. A: Maxillary nerve block. A needle tip is located right lateral to foramen rotundum on the anteroposterior view (A1) and pterygopalatine fossa on the lateral view (A2). B: Mandibular nerve block. A needle tip is placed at the midportion of the foramen ovale on the anteroposterior oblique view (B1). At this point, a needle is advanced a few millimeters medially to elicit paresthesia in the $\mathrm{V} 3$ innervated area. When the proper paresthesia is achieved, a needle tip should be in a cross point of the lateral one-third of the perpendicular line and the midhorizontal line of the foramen ovale on the submentomandibular view (B2). On the lateral view, a needle is placed in the entrance of foramen ovale at the margin of petrous bone (B3). C: Combined maxillary and mandibular nerve block. A needle tip is placed at the midportion of the foramen ovale on the anteroposterior oblique view $(\mathrm{Cl})$. At this point, a needle is advanced a few millimeters cephalad passing foramen ovale on the submentomandibular view ( $\mathrm{C2}$ ). On the lateral view, a needle is placed passing foramen ovale a few millimeters under the clival line (C3). 


\section{Results}

A total of $710\left(1^{\text {st }}-465,2^{\text {nd }}-155,3^{\text {rd }}-55,4^{\text {th }}-23,5^{\text {th }}-8\right.$, $\left.6^{\text {th }}-4\right)$ cases of Tnb with alcohol were performed to the 465 study subjects during the study period. The ratio of male to female patients was 1:2.3, and the mean age of the study patients was 61.3 years (range, 17-91 years). The mean duration of first onset of pain was 71.4 months, and that of recent pain was 111.6 days. A Number of V2+3 block, V2 block, V3 block, V2+V3 block, SONB or IONB and V2+3 block, V2 block or V3 block with SONB or IONB are 122, 173, 259, 15, 123, and 18. Mean pain intensity was 91 on the visual analogue scale (VAS; 0 is pain free and 100 is the worst imaginable pain). About half of the study subjects $(214 / 465)$ scored 100 on the VAS scale, and 427 of the 465 subjects (92\%) scored over 80 .

One hundred-forty seven patients had previous surgical treatments including $\operatorname{RF}(n=31,6.6 \%)$, neurectomy $(n=8,1.7 \%)$, balloon compression $(n=3$, $0.6 \%)$, gamma knife $(\mathrm{n}=11,2.4 \%)$, and Tnb with alcohol $(\mathrm{n}=83,17.8 \%)$. Eleven patients $(2.4 \%)$ had MVD previously (Table 1).

Table 1. Characteristics of the study patients.

\begin{tabular}{ll}
\hline Characteristics & Value (min-max) \\
\hline Number of patients & 465 \\
Gender & \\
M:F & $141: 324(1: 2.3)$ \\
Age (yr) & $61.3 \pm 13.2(17-91)$ \\
Duration & \\
First attack (months) & $71.4 \pm 78.5(1-600)$ \\
Recent attack (days) & $111.6 \pm 339.1(1-5760)$ \\
Pain site & \\
Rt: Lt: Bilateral & $305: 157: 3$ \\
Pain duration at one attack (sec) & $11.3 \pm 21.2(0.1-120)$ \\
Pain intensity (VAS) & $91.0 \pm 11.9(60-100)$ \\
Prior surgical treatments & 147 \\
RF & 31 \\
Neurectomy & 8 \\
Balloon compression & 3 \\
Gamma knife & 11 \\
Alcohol nerve block & 83 \\
MVD & 11 \\
Involved branch & $(\%)$ \\
V1 & $61(17.4)$ \\
V2 & $191(41.1)$ \\
V3 & $164(35.3)$ \\
V1+2 & $22(4.7)$ \\
V2+3 & \\
V1+2+3 & \\
\hline
\end{tabular}

Two hundred-twenty six of the study subjects $(48.6 \%)$ had no further treatment after the first alcohol Tnbs over the study period. However, 155 (33.3\%) experienced recurring pain after the first block, 55 of the 155 patients who had a $2^{\text {nd }}$ block also underwent a $3^{\text {rd }}$, and 23 of these 55 received a $4^{\text {th }}$. Eight patients were given a $5^{\text {th }}$ block and 4 of the 155 study subjects had $6^{\text {th }}$ block. Eighty-four patients of the study subjects $(18 \%)$ were lost to follow-up.

Four hundred sixty two of the 465 study subjects (99.4\%) experienced complete and immediate pain relief. Eighty one percent of the patients (376/465) during the first block succeeded with one injection and $14 \%(65 / 465)$ of the patients were pain free after a second injection on the second day of admission and $3.9 \%(18 / 465)$ of the patients had success with a third injection on the third day of admission. The three patient experienced continuous pain after the first block; they were believed to have alcoholic neuritis. All of the other 462 patients stopped pain medication immediately after the alcohol block.

According to Kaplan-Meier analysis conducted at 10 years after the first study procedure, median pain relief duration after the first block was 39 months. The probabilities of remaining pain relief at 1 , 2,3 , and 5 years after a successful alcohol block were $86.2 \%, 65.5 \%, 52.5 \%$, and $34.4 \%$, respectively (Fig. 2). No significant difference in pain relief durations was found between patients with and without previous alcohol blocks (Fig. 3) Median (95\% CI) pain relief durations for first and repeated blocks were 39 (36-51) and 37 (28-54) months, respectively.

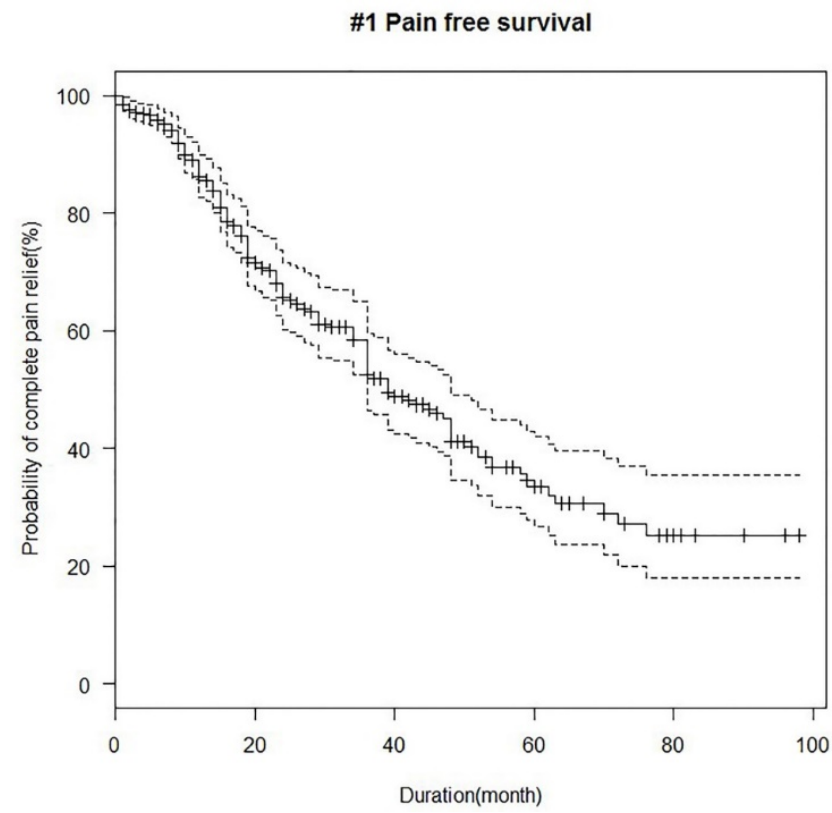

Figure 2. Kaplan Meier analysis of pain relief duration in the study subjects after the first trigeminal nerve block with alcohol.

Seven of a total 465 study patients chose medication for pain control when pain recurred; 6 after the $1^{\text {st }}$ block including 3 patients who took mediation from one day after the first block and one after the $2^{\text {nd }}$ block. Sixty-one $(8.6 \%)$ out of the 710 cases were associated with complications. Forty 
patients $(5.6 \%)$ complained of paresthesia, dysesthesia, itchting or deep sensory loss, although all study patients had varying degrees of sensory deficit on the selected area of the treated face. However, all sensory discomforts gradually decreased and patients adapted without medications. Other complications included transient masseter muscle weakness in 11 $(1.5 \%)$, heavy salivation in $3(0.004 \%)$, and tinnitus in 3 $(0.004 \%)$, and gradually improved within 6 months of treatment. No significant difference in the incidence of complications was found between patients with first and second block as well as between the patients with previous surgical procedures and without them (Table 2).

Table 2. Complications of the study procedures.

\begin{tabular}{lll}
\hline Complications & 1st block $(\%)(\mathrm{n}=465)$ & $2^{\text {nd }}$ block $(\%)(\mathrm{n}=155)$ \\
\hline Sensory discomfort & $34(7.3)$ & $6(3.9)$ \\
Mastication difficulty & $5(1.1)$ & $6(3.9)$ \\
Tinnitus & $3(0.7)$ & \\
Ptosis & $1(0.2)$ & $1(0.6)$ \\
Heavy salivation & $3(0.6)$ & \\
Double vision & $2(0.4)$ & $13(8.4)$ \\
Total & $48(10.3)$ & \\
\hline
\end{tabular}

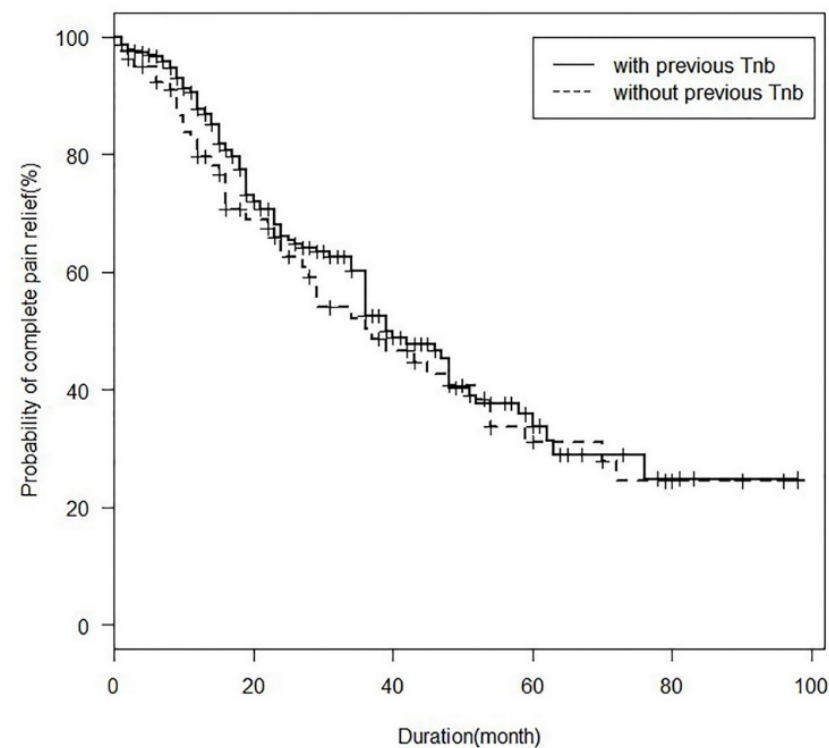

Figure 3. Kaplan Meier analysis of pain relief duration block after the first trigeminal nerve block in the study subjects with or without previous alcohol. Tnb; trigeminal nerve block.

Furthermore, gender, lesion site and having history of previous Tnb with alcohol and all kinds of previous surgical procedures were not found to be related to procedure outcome, however, age, duration of first attack, type of block were significantly influenced on the pain relief duration by univariate cox regression analysis (Table 3 ). The $\mathrm{V} 2+3$ block and V3 block produced significantly longer pain relief duration comparing to the other blocks including V2, $\mathrm{V} 2+\mathrm{V} 3$, sonb or ionb, or main branch block with sonb or ionb (Table 3) by multivariate cox regression under statistical correction with gender, age, duration of first attack and last attack, lesion site and having history of previous Tnb with alcohol. Median $(95 \% \mathrm{CI})$ pain relief durations for the V2+3 block, V3 block and the other blocks were 63 (58-NA), 48 (36-NA) and 29 (23-36) months, respectively (Fig 4).
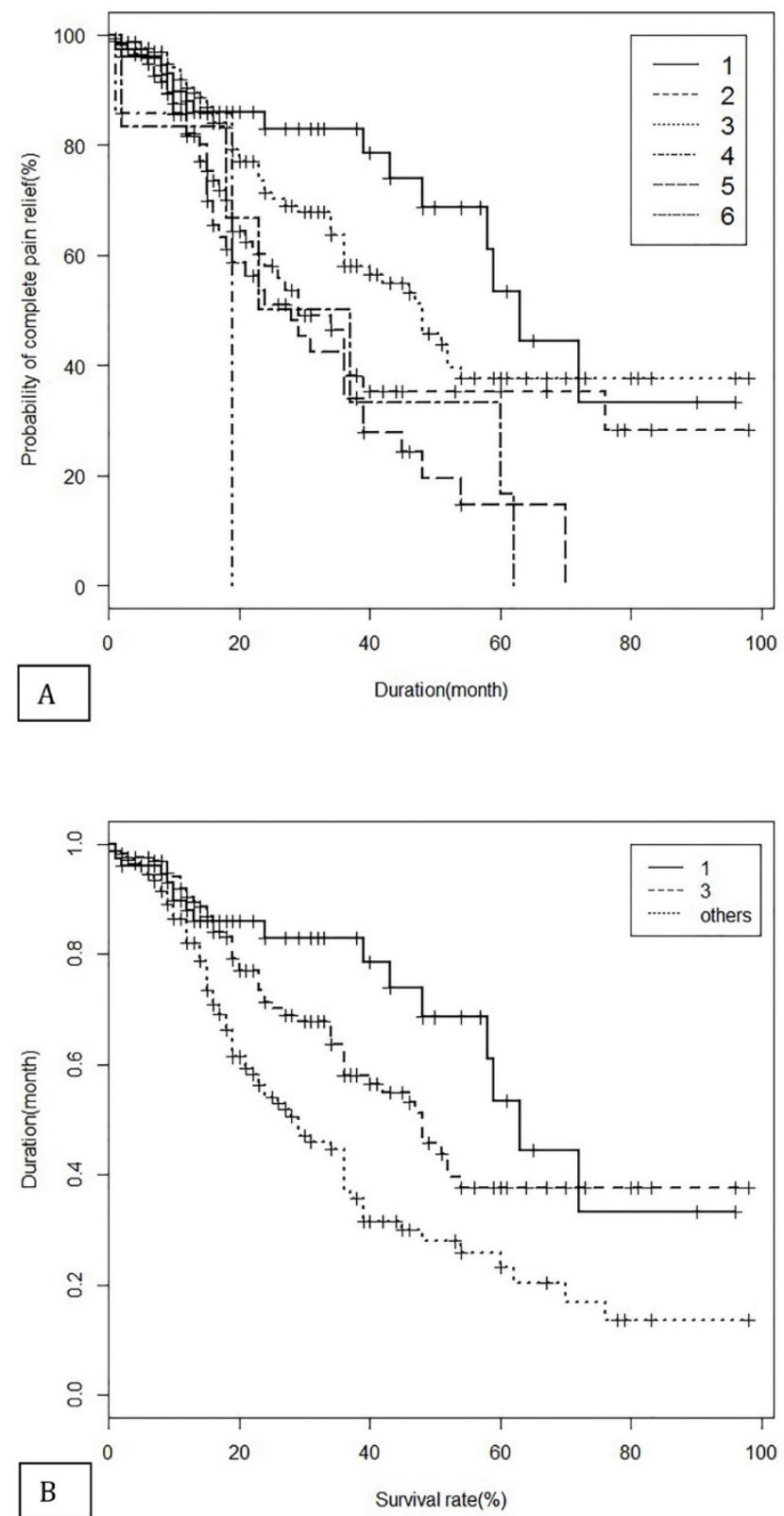

Figure 4. Kaplan Meier analysis of pain relief duration in each type of nerve block (A) and in the classified three groups (B) after the first trigeminal nerve block with alcohol. $1=\mathrm{V} 2+3,2=\mathrm{V} 2,3=\mathrm{V} 3,4=\mathrm{V} 2+\mathrm{V} 3,5=$ supraorbital nerve block (SONB) or infraorbital nerve block (IONB), $6=$ main branch block with sonb or ionb, others $=\mathrm{V} 2$ block, $\mathrm{V} 2+\mathrm{V} 3$ block, sonb or ionb, main branch block with sonb or ionb. 
Table 3. Univariate and multivariate Cox regression.

\begin{tabular}{lllll}
\hline Variable & Category & HR & $95 \%$ CI & p_value \\
\hline \multicolumn{1}{l}{ Univariate Cox regression } & & & \\
Age & $>65$ vs $\leq 65(\operatorname{Ref})$ & 1.74 & {$[1.26,2.42]$} & 0.0009 \\
Sex & male vs female(Ref) & 1.00 & {$[0.70,1.42]$} & 0.9953 \\
First attack(year) & & 0.97 & {$[0.95,1.00]$} & 0.0497 \\
Last attack & 1.00 & {$[1.00,1.00]$} & 0.7296 \\
Previous alcohol block & yes vs no(Ref) & 1.14 & {$[0.80,1.63]$} & 0.4640 \\
Site & right vs left(Ref) & 1.02 & {$[0.73,1.43]$} & 0.9187 \\
Complication & yes vs no(Ref) & 0.68 & {$[0.39,1.18]$} & 0.1700 \\
Group & 1 vs other (Ref) & 0.40 & {$[0.23,0.67]$} & 0.0005 \\
& 3 vs other (Ref) & 0.56 & {$[0.39,0.78]$} & 0.0007
\end{tabular}

\section{Multivariate Cox regression}

$\begin{array}{lcccc}\text { Age } & >65 \text { vs } \leq 65(\text { Ref }) & 1.74 & {[1.26,2.42]} & 0.0009 \\ \text { Sex } & \text { male vs female(Ref) } & 1.01 & {[0.70,1.44]} & 0.9539 \\ \text { First attack(year) } & & 1.00 & {[1.00,1.00]} & 0.0435 \\ \text { Last attack } & 1.00 & {[1.00,1.00]} & 0.5510 \\ \text { Previous alcohol block yes vs no(Ref) } & 1.21 & {[0.84,1.75]} & 0.2994 \\ & & & & \\ \text { Site } & \text { right vs left(Ref) } & 1.06 & {[0.75,1.50]} & 0.7394 \\ \text { Group } & \text { 1 vs others (Ref) } & 0.40 & {[0.24,0.68]} & 0.0007 \\ & \text { 3 vs others (Ref) } & 0.60 & {[0.43,0.86]} & 0.0050\end{array}$

Harrell's c index $=0.645$ (se $=0.027)$

1; V2+3 block, 3; V3 block, Others; V2 block, V2+V3 block, sonb or ionb, main branch block with sonb or ionb.

\section{Discussion}

Trigeminal nerve alcohol blocks remain a controversial form of TN management, and to date no well-designed statistically based study has presented outcome data. Various percutaneous techniques including $\mathrm{RF}$, balloon compression, glycerol neurolysis, and MVD are currently used to manage $\mathrm{TN}$, but no consensus has been reached regarding optimal treatment.

Furthermore, few reports have addressed pain relief duration by alcohol block of the peripheral trigeminal nerve (13-16). Fardy et al. reported in their retrospective study of $68 \mathrm{TN}$ patients that the median pain-free time for a peripheral trigeminal alcohol nerve block was 19 months for the inferior alveolar nerve, and 13 months for the infraorbital nerve (13). More recently, McLeod et al. showed that 278 alcohol injections in $49 \mathrm{TN}$ patients had mean action duration of 11 months (1-53 months) (14). Mean pain relief duration in the present study was substantially longer than those previously reported results. All previous authors performed the peripheral branches of trigeminal nerve using alcohol, while the authors underwent alcohol injection into the gasserian ganglion and mandibular nerve through foramen ovale as well as peripheral branches.

Although many reports have addressed the outcomes of surgical treatments for TN, study designs and definitions for success and recurrence vary considerably. Lopez et al. suggested inclusion criteria for appropriate studies on the outcomes of the surgical treatment of TN (19), and the present study complied with these criteria. In the present study, success was defined as pain relief without any analgesic administration, and recurrence was defined as any return of pain, regardless of whether pain was controlled by medication or required a further procedure. Based on the definitions of success and recurrence described above, the pain relief duration observed in the present study is comparable with that reported for RF; rates of complete pain relief at 1, 2, and 3 years after the procedure were $70-90 \%, 62-64 \%$ and $58-64 \%$, respectively $(3,4,21)$.

Contrary to the above-mentioned earlier studies on the outcome of RF, percutaneous procedures, such as glycerol neurolysis, balloon compression, and gamma knife surgery have used definitions of pain relief and recurrence that differ from ours. In these studies, pain relief was defined as freedom of pain with or without medication, whereas recurrence was defined as recurrent pain refractory to medication $(5,6,8,10)$. Even if these definition and differences of study design are disregard, pain relief duration observed during the present study was appreciably longer $(5,6,8-10)$.

There is a tendency to believe that Tnb with alcohol become less effective in terms of pain relief duration and increase morbidity when treatment is repeated. Although Shah et al. reported that pain free interval of repeated block was shorter than first block, the other previous studies showed repeated Tnb with alcohol did not lose effectiveness, even after 14 blocks had been administered in one individual over many years $(14,15)$. Furthermore, we failed to find a significant difference in pain relief duration between first and repeat blocks.

In this study, there was a significant difference of pain relief duration in the other peripheral Tnb comparing to the V2+3 block and the V3 block. The $\mathrm{V} 2+3$ block could induce destruction of neurons with abnormal electrical behavior directly in the gasserian ganglion, in which hyperexcitable neurons existed by ignition hypothesis of TN pathophysiology (22). Needle approach of the V3 block is through the foramen ovale reaching proximal portion of mandibular nerve near gasserian ganglion. However, peripheral Tnb with alcohol would be a role as conduction block in the axon of peripheral trigeminal nerve. Possible reason why the V2+3 block and V3 block showed longer pain relief duration than other peripheral Tnbs would be that neurolysis in the gasserian ganglion or near gasserian ganglion could directly affect the pain generating lesion.

Few studies have been conducted on Tnb with alcohol or its related complications (4,23-26). Macleod et al. reported that $4 \%$ of their patients experienced 
local symptoms, such as, pain, burning, swelling, local infection, and avascular necrosis of the skin (14). Fardy and Patton reported that only $3(0.73 \%)$ of their cases experienced a significant complication after performing 413 peripheral Tnb with alcohol over 20 years (23). Generally, all neuroablative procedures for TN treatment involve trigeminal nerve disturbances, both sensory and motor, and troublesome dysesthetic disturbances affect approximately 4 to $10 \%$ of patients treated with any ablative technique for TN (18). Furthermore, anesthesia dolorosa, corneal sensory disturbance can occur after denervation procedure for $\mathrm{TN}$, especially in patients that undergo RF, in whom it occurs at a rate of $0.3-22 \%(3,21,27)$.

In this study, a total of 61 complications (8.6\%) were encountered in the 710 study cases. The most common complication was sensory discomfort including itching, bothersome dysesthesia, deep hypesthesia $(5.7 \%)$, the majority resolved within 6 months. The other complications were also subsided or well tolerated by patients in several months. Percutaneous surgical techniques are less likely to be associated with mortality or hearing loss, which is their greatest benefit as compared with MVD $(11,12)$. In our study there was no death related to the study procedures.

To the best of our knowledge, no previous study has compared the complication rates between first and repeated trigeminal nerve alcohol blocks. Nevertheless, many practitioners believe that complication rates are higher after repeated blocks. However, our results suggest that complication rates are higher after the first block, and we attribute this finding to an acquired tolerance of sensory losses and procedure-related discomforts. Furthermore, there was no significant pain relief duration between the first block and repeated block.

Our study has a several limitations. First, we did not evaluate hypesthesia. However, a certain degree of hypoesthesia after the study procedures is expected to occur, and many patients were elderly and could not clearly explain the extent of sensation loss. Second, we did not compare quality of life before and after the study procedures. In fact, few studies have described changes in the quality of life resulting from surgical procedures in $\mathrm{TN}(21,28,29)$. Usually, the major factors that impact the quality of life in TN patients who undergo surgical procedures are incomplete pain relief and intolerable complications.

In conclusion, we strongly believe that our present data support the notion that Tnb with alcohol should be reconsidered as a useful treatment option for medically intractable $\mathrm{TN}$, because our results indicate that this modality offers a high rate of complete pain relief and has a long lasting effect without serious complications. Furthermore, our findings show that repeated Tnb with alcohol does not influence complete pain relief duration or the risk of complications.

\section{Competing Interests}

The authors have declared that no competing interest exists.

\section{References}

1. Grant FC. Alcohol injection in the treatment of major trigeminal neuralgia. J Am Med Assoc 1936; 107: 771-774.

2. Ruge D, Brochner SR, Davis L. A study of the treatment of 637 patients with trigeminal neuralgia. J Neurosurg 1958; 15: 528-536.

3. Kanpolat Y, Savas A, Bekar A, Berk C. Percutaneous controlled radiofrequency trigeminal rhizotomy for the treatment of idopathic trigeminal neuralgia: 25 year experience with 1,600 patients. Neurosurgery 2001; 48: 524-534.

4. Oturai $A B$, Jensen $K$, Eriksen J, Madsen F. Neurosurgery for trigeminal neuralgia: Comparison of alcohol block, neurectomy, and radiofrequency coagulation. Clin J Pain 1996; 12: 311-315.

5. North RB, Kidd DH, Piantadosi S, Carson BS. Percutaneous retrogasserian glycerol rhizotomy: Predictors of success and failure in treatment of trigeminal neuralgia. J Neurosurg 1990; 72: 851-856.

6. Slettebo H, Hirschberg $H$, Lindegaard KF. Long-term results after percutaneous retrogasserian glycerol rhizotomy in patients with trigeminal neuralgia. Acta Neurochir (Wien) 1993; 122: 231-235.

7. Lichtor T, Mullan JF. A 10-year follow-up review of percutaneous microcompression of the trigeminal ganglion. J Neurosurg 1990; 72: 49-54.

8. Brown JA, McDaniel MD, Weaver MT. Percutaneous trigeminal nerve compression for treatment of trigeminal neuralgia: Results in 50 patients. Neurosurgery 1993; 32: 570-573.

9. Maesawa S, Salame C, Flickinger JC, Pirris S, Kondziolka D, Lunsford LD. Clinical outcomes after stereotactic radiosurgery for idiopathic trigeminal neuralgia. J Neurosurg 2001; 94: 14-20.

10. Pollock BE, Phuong LK, Foote RL, Stafford SL, Gorman DA: High-dose trigemninal neuralgia radiosurgery for idiopathic trigeminal neuralgia. J Neurosurg 2002; 97: 347-353.

11. Barker FG, Jannetta PJ, Bissonette DJ, Larkins MV, Jho HD. The long-term outcome of microvascular decompression for trigeminal neuralgia. $\mathrm{N}$ Engl J Med 1996; 334: 1077-1083.

12. Sindou M, Leston J, Howeidy T, Decullier E, Chapuis F. Micro-vascular decompression for primary trigeminal neuralgia (typical or atypical). Long-term effectiveness on pain; prospective study with survival analysis in a consecutive series of 362 patients. Acta Neurochir (Wien) 2006; 148: 1235-1245.

13. Fardy MJ, Zakrzewska JM, Patton DW. Peripheral surgical techniques for the management of trigeminal neuralgia - Alcohol and glycerol injections. Acta Neurochir 1994; 129: 181-185.

14. McLeod NMH, Patton DW. Peripheral alcohol injections in the management of trigeminal neuralgia. Oral Surg Oral Med Oral Pathol Oral Radiol Endod 2007; 104: 12-17

15. Shah SA, Khan MN, Shah SF, Ghafoor A, Khattak A. Is peripheral alcohol injection of value in the treatment of trigeminal neuralgia? An analysis of 100 cases. Int. J. Oral Maxillofac. Surg. 2011; 40: 388-392.

16. Kyung Ream Han, Chan Kim. The long term outcome o mandibular nerve block with alcohol for the treatment of trigeminal neuralgia. Anesthesia and Analgesia 2010; 111: 550-553.

17. Loeser JD. Cranial Neuralgias. In: Loeser JD, ed. Bonica's management of pain. $3^{\text {rd }}$ ed. Philadelphia: Lippincott Williams \& Wilkins, 2001: 855-860.

18. Tatli M, Satici O, Kanpolat Y, Sindou M. Various surgical modalities for trigeminal neuralgia: literature study of respective long-term outcomes. Acta Neurochirurgica 2008; 150: 243-255

19. Lopez BC, Hamlyn PJ, Zakrzewska JM. Systematic review of ablative neurosurgical techniques for the treatment of trigeminal neuralgia. Neurosurgery 2004; 54: 973-983.

20. Zakrzewska JM. Trigeminal, eye and ear pain. In: Wall PD and Melzack R, ed. Textbook of pain. $4^{\text {th }}$ ed. London: Churchill Livingstone, 2000:739-741.

21. Zakrzewska JM, Jassim S, Bulman JS. A prospective, longitudinal study on patients with trigeminal neuralgia who underwent radiofrequency thermocoagulation of the gasserian ganglion. Pain 1999; 79: 51-58.

22. Devor M, Amir R, Rappaport H. Pathophysiology of trigeminal neuralgia: The ignition hypothesis. The Clinical Journal of Pain 2002; 18: 4-13.

23. Fardy MJ, Patton DWP. Complications associated with peripheral alcohol injections in the management of trigeminal neuralgia. Br J Oral Maxillofac Surg 1994; 32: 387-391.

24. Torrente-Castells E, Gargallo-Albiol J, Rodríguez-Baeza A, Berini-Aytés L, Gay-Escoda C. Necrosis of the skin of the chin: a possible complication of inferior alveolar nerve block injection. J Am Dent Assoc. 2008; 139: 1625-1630. 
25. Richardson MF, Straka JA. Alcohol block of the mandibular nerve. Report of a complication. J Natl Med Assoc. 1973; 65: 63-64.

26. Rood JP. Ocular complication of inferior dental nerve block. A case report. Br Dent J. 1972; 132: 23-24.

27. Broggi G, Franzini A, Lasio G, Giorgi C, Sevello D. Long-term results of percutaneous retrogasseian thermorhizotomy for "essential" trigeminal neuralgia: considerations in 1000 consecutive patients. Neurosurgery 1990; 26: 783-786.

28. awahar A, Wadhwa R, Berk C, Caldito G, DeLaune A, Ampil F, Willis B, Smith D, Nanda A. Assessment of pain control, quality of life, and predictors of success after gamma knife surgery for the treatment of trigeminal neuralgia. Neurosurg Focus 2005; 18: E8.

29. Spatz AL, Zakrzewska JM, Kay EJ. Decision analysis of medical and surgical treatments for trigeminal neuralgia: How patient evaluations of benefits and risks affect the utility of treatment decision. Pain 2007; 131: 302-310. 